\title{
PROFIL KESESUAIAN PENULISAN RESEP PADA PASIEN UMUM RAWAT INAP DENGAN FORMULARIUM DI RUMAH SAKIT BEDAH MITRA SEHAT LAMONGAN
}

\author{
Profile of Prescribing compliance to inpatients with hospital formulary in Bedah Mitra \\ Sehat Hospital, Lamongan \\ Dewi Meisaroh $^{1}$, Anindi Lupita Nasyanka ${ }^{2 *}$, Hawwin Elina Arizka ${ }^{3}$ \\ Universitas Muhammadiyah Gresik ${ }^{12}$ \\ Rumah Sakit Bedah Mitra Sehat Lamongan ${ }^{3}$ \\ Alamat Penulis * \\ Email : anindilupita@umg.ac.id
}

\begin{abstract}
The hospital minimum service standard becomes the minimum reference for assessing the services provided by the hospital. One important point is the suitability of prescribing to patients based on hospital formulary. In this study aims to determine the suitability profile of inpatient prescribing in Rumah Sakit Bedah Mitra Sehat Lamongan with hospital formulary. The research method used was cross-sectional with accidental sampling as many as 614 prescriptions from May until June 2019. The results showed that the percentage of compliance with the average prescribing in May-June did not reach the minimum service standards (100\%). therefore, a periodic evaluation of the formulary and outreach is needed to all doctors who write prescriptions for inpatients
\end{abstract}

Keyword : prescribing, hospital formulary, inpatient

\section{PENDAHULUAN}

Rumah sakit adalah bagian integral dari suatu organisasi sosial dan kesehatan dengan fungsi menyediakan pelayanan komprehensif, kuratif dan preventif kepada masyarakat .Pelayanan rumah sakit sangat menetukan mutu dari rumah sakit tersebut. Beberapa pelayanan yang menjadi tolak ukur pada standar minimal pelayanan di rumah sakit diantaranya yaitu pelayanan kefarmasian (Menteri Kesehatan RI, 2016). Pelayanan kefarmasian adalah salah satu bentuk pelayanan yang penting di rumah sakit secara langsung dan bertanggung jawab kepada pasien yang berkaitan dengan sediaan farmasi untuk mencapai hasil yang pasti untuk meningkatkan mutu kehidupan pasien (Menkes RI, 2014).

Standar Pelayanan Kefarmasian di Rumah Sakit dibagi menjadi 2 yaitu standar pengelolaan Sediaan Farmasi, Alat Kesehatan, dan Pelayanan farmasi klinik. Pada pelayanan farmasi klinik di Rumah Sakit didukung oleh adanya formularium rumah sakit. Formularium rumah sakit merupakan daftar obat yang disepakati oleh staf medis, disusun oleh komite farmasi dan terapi yang ditetapkan oleh pimpinan rumah sakit (Presiden RI, 2009).

Formularium bermanfaat sebagai acuan bagi penulis resep, mengoptimalkan pelayanan kepada pasien, memudahkan perencanaan, dan penyediaan obat pada fasilitas pelayanan kesehatan. Dengan adanya formularium, pasien akan mendapatkan obat terpilih yang tepat, berkhasiat, bermutu, aman, dan terjangkau, sehingga akan tercapai kesehatan yang setinggi-tingginya.

Kesesuaian resep obat dengan formularium diatur dalam SPM (Standar pelayaan minimal), dimana indikator penulisan resep sesuai formularium harus memenuhi standart yaitu 100\% (Menkes RI, 2010). Dampak dari ketidaksesuaian resep dengan formularium bagi pasien adalah kemungkinan pasien tidak bisa mendapatkan obat yang tertulis di resep karena rumah sakit tidak menyediakan obat diluar formularium rumah sakit sehingga pasien gagal 
mendapatkan terapi (Vermasari, Arya, Masrul, dan Yetti, H., 2019).

Oleh karena itu, pada penelitian imi akan dilakukan pengamatan kesesuaian peresepan pasien rawat inap dengan formularium rumah sakit pada RS Bedah Mitra Sehat Lamongan dengan harapkan penelitian ini mampu meningkatkan pelayanan di RS Bedah Mitra Sehat Lamongan.

\section{II.TINJAUAN PUSTAKA}

\subsection{Resep}

Resep adalah permintaan tertulis dari dokter atau dokter gigi, kepada apoteker, baik dalam bentuk paper maupun electronik untuk menyediakan dan menyerahkan obat bagi pasien sesuai peraturan yang berlaku (Anief, 2000)

Resep dibedakan menjadi empat jenis yaitu yang pertama resep standar (R/. Officinalis), yaitu resep yang komposisinya telah dibakukan dan dituangkan ke dalam buku farmakope atau buku standar lainnya. Penulisan resep sesuai dengan buku standar.yang kedua yaitu resep magistrales (R/. Polifarmasi), yaitu resep yang sudah dimodifikasi atau diformat oleh dokter, bisa berupa campuran atau tunggal yangn diencerkan dalam pelayanannya harus diracik terlebih dahulu.yang ketiga yaitu resep medicinal, yaitu resep obat jadi, bisa berupa obat paten, merek dagang maupun generik, dalam pelayanannya tidak mangalami peracikan. Buku referensi, Organisasi Internasional untuk Standarisasi (ISO), Indonesia Index Medical Specialities (IIMS), Daftar Obat di Indonesia(DOI), dan lain-lain. Dan yang terakhir yaitu Resep obat generik, yaitu penulisan resep obat dengan nama generik dalam bentuk sediaan dan jumlah tertentu. Dalam pelayanannya bisa atau tidak mengalami peracikan (Anief, 2000).

\subsection{Standar Pelayanan Minimal Rumah Sakit}

Standar pelayanan minimal adalah ketentuan tentang jenis dan mutu pelayanan dasar yang merupakan urusan wajib daerah yang berhak diperoleh setiap warga secara minimal, juga merupakan spesifikasi teknis tentang tolak ukur pelayanan minimum yang diberikan oleh Badan Layanan Umum masyarakat. Dalam mengevaluasi kesesuaian penulisan resep terhadap formularium, digunakan beberapa indikator yang dijelaskan sebagai berikut (Haliman, Arifdan Ari Wulandari, 2012).
Tabel 1 Indikator Pelayanan Minimal Farmasi Tentang Penulisan Resep Sesuai Formularium

\begin{tabular}{|l|l|}
\hline Judul & Penulisan resep sesuai formularium \\
\hline Dimensi mutu & Efisiensi \\
\hline Tujuan & $\begin{array}{l}\text { Tergambarnya efisiensi pelayanan obat } \\
\text { kepada pasien }\end{array}$ \\
\hline Definisi operasional & $\begin{array}{l}\text { Formularium adalah daftar obat yang } \\
\text { digunakan dirumah sakit }\end{array}$ \\
\hline $\begin{array}{l}\text { Frekuensi } \\
\text { pengumpulan data }\end{array}$ & 1 bulan \\
\hline Periode analisis & 3 bulan \\
\hline Numerator & $\begin{array}{l}\text { Jumlah resep yang diambil sebagai } \\
\text { sampel yang sesuai formularium dalam } \\
\text { satu bulan }\end{array}$ \\
\hline Denominator & $\begin{array}{l}\text { Jumlah seluruh resep yang diambil } \\
\text { sebagai sampel dalam satu bulan (n } \\
\text { minimal 50 ) }\end{array}$ \\
\hline Sumber data & Survey \\
\hline Standart & $100 \%$ \\
\hline Penanggung jawab & Kepala instansi farmasi \\
\hline
\end{tabular}

\subsection{Formularium Rumah Sakit}

Formularium Rumah Sakit disusun mengacu kepada Formularium Nasional. Formularium Rumah Sakit merupakan daftar obat yang disepakati staf medis, disusun oleh komite/tim farmasi dan terapi yang ditetapkan oleh pimpinan Rumah Sakit. Formularium Rumah Sakit harus tersedia untuk semua penulis resep, pemberi obat, dan penyedia obat di Rumah Sakit. Evaluasi terhadap Formularium Rumah Sakit harus secara rutin dan dilakukan revisi sesuai kebijakan dan kebutuhan Rumah Sakit (Menteri Kesehatan RI, 2018)

Komposisi dari formularium adalah halaman judul, daftar nama anggota panitia farmasi dan terapi, daftar isi, informasi mengenai kebijakan dan prosedur dibidang obat, produk obat yang diterima untuk digunakan dan lampiran. Formularium bermanfaat sebagai acuhan bagi penulis resep, mengoptimalkan pelayanan kepada pasien, memudahkan perencanaan, dan penyediaan obat pada fasilitas pelayanan kesehatan. Pasien akan mendapatkan obat terpilih yang tepat, berkhasiat, bermutu, aman, dan terjangkau dengan adanya formularium, sehingga akan tercapai kesehatan yang setinggi-tingginya. Oleh karena itu obat yang tercantum dalam formularium harus dijamin ketersediaanya (Dirjen Binfar dan Farkalkes. 2010)

Kriteria pemilihan obat untuk masuk Formularium Rumah Sakit adalah mengutamakan penggunaan obat generik, memiliki rasio manfaat risiko (benefit-risk ratio) yang paling menguntungkan penderita, mutu terjamin, termasuk stabilitas dan bioavailabilitas, praktis dalam penyimpanan dan pengangkutan, praktis dalam penggunaan dan penyerahan, menguntungkan dalam hal kepatuhan dan penerimaan oleh pasien, memiliki rasio manfaat-biaya (benefit-cost ratio) yang 
tertinggi. Berdasarkan biaya langsung dan tidak lansung dan obat lain yang terbukti paling efektif secara ilmiah dan aman (evidence based medicines) yang paling dibutuhkan untuk pelayanan dengan harga yang terjangkau (Menteri Kesehatan RI, 2016)

\section{III.METODE PENELITIAN}

Penelitian ini bersifat deskriptif dengan pendekatan cross sectional yaitu penelitian yang dilakukan dalam waktu yang bersamaan dan sekaligus. Sampel yang digunakan adalah accidental sampling yaitu semua resep pasien umum rawat inap pada bulan Mei- Juni 2019 RS Bedah Mitra Sehat Lamongan. Sampel yang digunakan berjumlah 614 resep. Teknik analisa data dengan menggunakan rumus sebagai berikut :

Persentase Kesesuaian resep $(\%)=$

\section{jumlah obat resep yang sesusi dengan formularium}

Jumlah obat dalam resep

\section{HASIL DAN PEMBAHASAN}

\subsection{Karakteristik penulisan resep di Rumah Sakit Bedah Mitra Sehat Lamongan}

Dari hasil penelitian yang dilakukan pada pasien umum rawat inap di RS Bedah Mitra Sehat Lamongan pada bulan Mei dan Juni tahun 2019 disajikan pada tabel 2.

Penelitian dilaksanakan di unit Farmasi RS Bedah Mitra Sehat Lamongan dengan sampel resep sebanyak 614, yang terdiri dari resep bulan Mei berjumlah 317 dan bulan Juni berjumlah 297. Persentase paling tinggi yaitu dokter Umum dengan presentase $51,79 \%$ dan presentase paling rendah yaitu dokter spesialis Saraf dengan persentase $0,16 \%$

Tabel 2 Persentase Dokter Penulis Resep

\begin{tabular}{|c|l|r|r|r|r|}
\hline No & $\begin{array}{c}\text { Nama } \\
\text { Dokter }\end{array}$ & Mei & Juni & Jumlah & Persentase \\
\hline 1 & $\begin{array}{l}\text { Dokter } \\
\text { spesialis } \\
\text { Bedah } \\
\text { Umum }\end{array}$ & 147 & 126 & 274 & $44,6 \%$ \\
\hline 2 & $\begin{array}{l}\text { Dokter } \\
\text { spesialis } \\
\text { Urologi }\end{array}$ & 3 & 4 & 7 & $1,1 \%$ \\
\hline 3 & $\begin{array}{l}\text { Dokter } \\
\text { spesialis } \\
\text { Saraf }\end{array}$ & - & 1 & 1 & $0,2 \%$ \\
\hline 4 & $\begin{array}{l}\text { Dokter } \\
\text { spesialis } \\
\text { Penyakit } \\
\text { Dalam }\end{array}$ & 12 & 3 & 15 & $2,4 \%$ \\
\hline 5 & $\begin{array}{l}\text { Dokter } \\
\text { umum }\end{array}$ & 155 & 163 & 318 & $51,7 \%$ \\
\hline
\end{tabular}

\subsection{Kesesuaian peresepan dengan formularium}

Hasil penelitian mengenai kesesuaian peresepan dengan formularium diperoleh dari pencatatan obat yang diresepkan oleh semua dokter di RS Bedah Mitra Sehat Lamongan yaitu spesialis Bedah Umum, dokter spesialis Urologi, dokter spesialis Saraf, dokter spesialis Penyakit Dalam, dan dokter Umum pada pasien umum rawat inap RS Bedah Mitra Sehat Lamongan bulan Mei dan Juni 2019. Formularium yang digunakan dalam penelitian ini adalah Formularium (volume 01 pada tahun 2018) dengan surat keputusan nomor307/KPTS/RSBMS/2018 (Komite Farmasi dan Terapi RSBMS.2018). Hasil persentase peresepan obat dengan formularium dapat dilihat pada tabel berikut:

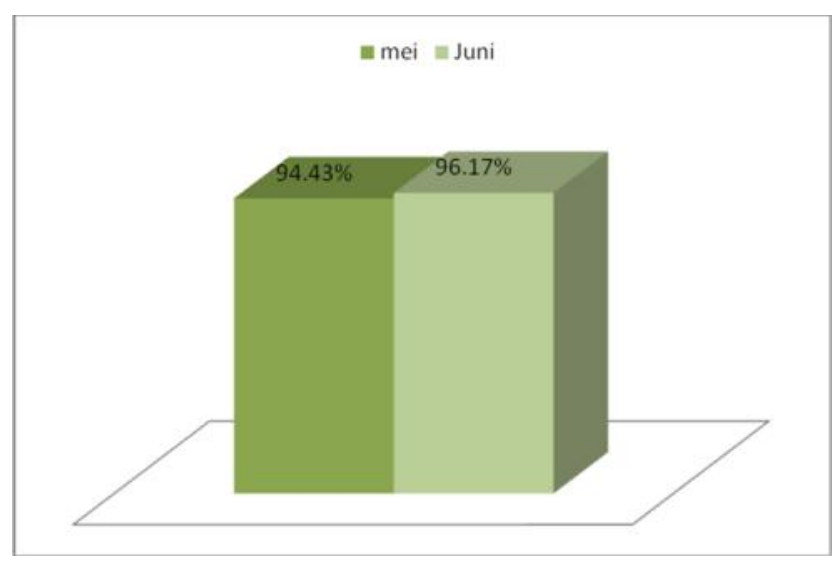

Gambar 1. Kesesuaian Peresepan Pasien Rawat Inap Dengan Formularium RS Bulan Mei-Juni 2019

Hasil yang didapat dari 2 bulan penelitian yaitu pada bulan Mei dan Juni belum memenuhi standar yang telah ditentukan oleh pemerintah dalam indikator pelayanan minimal tentang penulisan resep sesuai dengan formularium yaitu $100 \%$. Presentase kesuaian peresepan dengan formularium bulan Mei sebesar 94,43\%, dan pada bulan Juni diperoleh presentase sebesar $96,17 \%$, dan hasil rata-rata presentase kesesuaian peresepan dari bulan mei dan juni tahun 2019 didapatkan sebesar 95,3\%.

Ketidaksesuaian peresepan dengan formularium ini dikarenakan oleh beberapa alasan yaitu :

1. Adanya kasus tertentu sehingga membutukan obat lain di luar formularium

2. Adanya pengaruh pihak lain yang menghubungi dokter penulis resep untuk menggunakan produk obat mereka.

3. Kurangnya sosialisasi pada semua dokter dalam penggunaan formularium yang berlaku. 


\subsection{Data peresepan dokter dan kesesuaian obat dengan formularium}

Peresepan di RS Bedah Mitra Sehat Lamongan dilakukan oleh beberapa dokter, yaitu dokter spesialis Bedah Umum, dokter spesialis Urologi, dokter spesialis Syaraf, dokter spesialis Penyakit Dalam, dan beberapa dokter Umum. Pada gambar 2 menunjukan bahwa jumlah kesesuaian obat paling tinggi yaitu dokter Umum yang berjumlah 1216 obat dan yang jumlah yang paling sedikit yaitu dokter Spesialis Syaraf yang berjumlah 4 obat, sedangkan ketidaksesuaian jumlah obat paling tinggi juga terdapat pada dokter Umum yang berjumlah 90 obat dan yang paling sedikit adalah dokter Spesialis Urologi dan dokter Spesialis Syaraf yang masingmasing berjumlah nihil atau 0 .

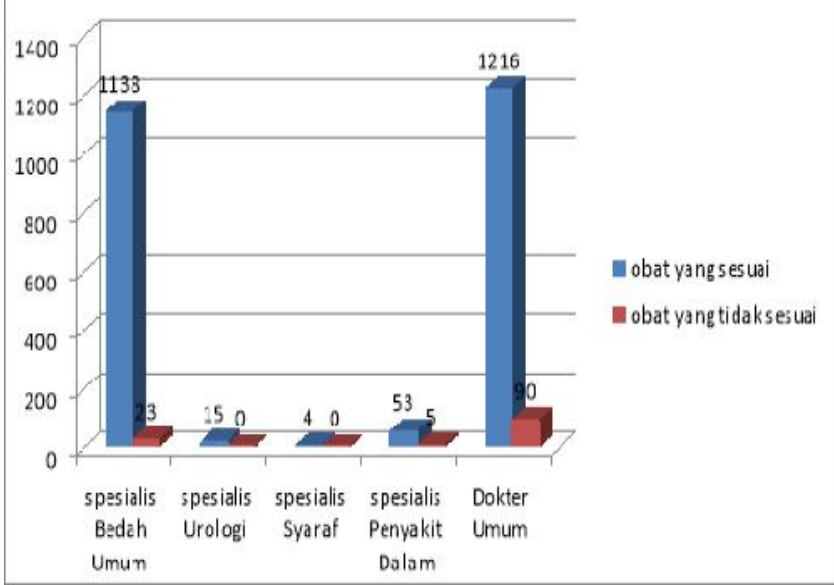

Gambar 2. Kesesuaian Peresepan Obat Dengan Formularium Oleh dokter Penulis Resep.

Jumlah obat yang tidak sesuai dengan formularium RS Bedah Mitra Sehat Lamongan (Vol 01) berjumlah 32 item obat. Berdasarkan tabel 4 , maka sebagian besar obat yang tidak sesuai peresepannya dengan formularium di rumah sakit sudah tercantum dalam formularium. Namun, hanya sebagian saja yang belum tersedia seperti buscopan inj, thrombop gel, cephaflox injeksi, counterpain salep, azitromisin tablet, dancurcuma tablet.

Tabel 3.Daftar Obat Yang Tidak Sesuai Dengan Formularium

\begin{tabular}{|c|l|c|c|}
\hline No & \multicolumn{1}{|c|}{$\begin{array}{c}\text { Obat yang tidak } \\
\text { sesuai dengan } \\
\text { formularium }\end{array}$} & $\begin{array}{c}\text { Tersedia obat } \\
\text { sejenis }\end{array}$ & $\begin{array}{c}\text { Tidak } \\
\text { tersedia obat } \\
\text { sejenis }\end{array}$ \\
\hline 1 & Propepsa syr & $\sqrt{ }$ & - \\
\hline 2 & Lisinopril tab & $\sqrt{ }$ & - \\
\hline 3 & Growvit tab & $\sqrt{ }$ & - \\
\hline 4 & Maxtan tab & $\sqrt{ }$ & - \\
\hline 5 & Zedifec inj & $\sqrt{ }$ & - \\
\hline 6 & Thombopop gel & $\sqrt{ }$ & - \\
\hline 7 & Cephaflox inj & & \\
\hline
\end{tabular}

\begin{tabular}{|c|c|c|c|}
\hline 8 & Counterpain salep & - & $\sqrt{ }$ \\
\hline 9 & Neuralgin tab & $\sqrt{ }$ & - \\
\hline 10 & Azitrhromycin tab & - & $\sqrt{ }$ \\
\hline 11 & Antrain inj & $\sqrt{ }$ & - \\
\hline 12 & Caviplex tab & $\sqrt{ }$ & - \\
\hline 13 & Celestamine tab & $\sqrt{ }$ & - \\
\hline 14 & Mucopect tab & $\sqrt{ }$ & - \\
\hline 15 & Cerini tab & $\sqrt{ }$ & - \\
\hline 16 & Loratadine tab & $\sqrt{ }$ & - \\
\hline 17 & Buscopan inj & - & $\sqrt{ }$ \\
\hline 18 & Donperidone inj & $\sqrt{ }$ & - \\
\hline 19 & Ceftazidime inj & $\sqrt{ }$ & - \\
\hline 20 & Theophyllin tab & $\sqrt{ }$ & - \\
\hline 21 & Neurohax tab & $\sqrt{ }$ & - \\
\hline 22 & Mulacort $0,5 \mathrm{mg}$ tab & $\sqrt{ }$ & - \\
\hline 23 & Inbion tab & $\sqrt{ }$ & - \\
\hline 24 & Cal 95 tab & $\sqrt{ }$ & - \\
\hline 25 & Curcuma tab & - & $\sqrt{ }$ \\
\hline 26 & Tomit inj & $\sqrt{ }$ & - \\
\hline 27 & Bevizil tab & $\sqrt{ }$ & - \\
\hline 28 & Florin tab & $\sqrt{ }$ & - \\
\hline 29 & Vitamin $\mathrm{K}$ tab & $\sqrt{ }$ & - \\
\hline 30 & Rhemafen tab & $\sqrt{ }$ & - \\
\hline 31 & Kenalog salep & $\sqrt{ }$ & - \\
\hline 32 & Sangobion tab & $\sqrt{ }$ & - \\
\hline
\end{tabular}

Banyaknya obat yang tersedia di formularium diharapkan keseuaian peresapan dapat memenuhi target standar pelayanan minimal di rumah sakit yaitu $100 \%$. Peresepan yang tidak sesuai dengan formularium dapat dikurangi dengan adanya evaluasi berkala komite farmasi rumah sakit sehingga akibat kegagalan terapi yang didapatkan pasien oleh karena obat tersebut tidak tersedia di rumah sakit dapat berkurang (Budiarto,Ikhsanudin W. 2016).

\section{V.PENUTUP}

Berdasarkan pengamatan dan penelitian yang dilakukan selama 2 bulan yaitu bulan Mei dan Juni pada tahun 2019 maka diperoleh hasil kesesuaian peresepan pasien umum rawat inap pada bulan Mei yaitu sebesar 94,43\%, sedangkan bulan Juni sebesar $96,17 \%$. Rata-rata kesesuaian peresepan di RS Bedah Mitra Sehat Lamongan belum memenuhi standar pelayanan minimal di Rumah Sakit, sehingga dapat dilakukan upaya-upaya untuk meningkatkannya antara lain, evaluasi berkala pada formularium, melakukan sosialisasi berkala baik pada dokter praktek maupun oncall.

\section{DAFTAR PUSTAKA}

(1)Menteri Kesehatan RI. 2016. Peraturan Menteri Kesehatan Republik Indonesia No.43 tentang Standar Pelayanan Minimal bidang Kesehatan. Jakarta. 
(2)Menkes RI, 2014. Peraturan Menteri Kesehatan Republik Indonesia No 58 Tentang Standar Pelayanan Kefarmasian Di Rumah Sakit, Jakarta.

(3)Presiden RI, 2009.Undang-Undang Republik Indonesia Tentang Rumah Sakit, Jakarta.

(4)Menkes RI, 2010. Peraturan Menteri Kesehatan Republik Indonesia No 340 Tentang Klarifikasi Rumah Sakit. Jakarta.

(5) Vermasari, Arya, Masrul, dan Yetti, H.(2019). Analisis Implementasi Standar Pelayanan Minimal (Spm) Di Instalasi Gawat Darurat (IGD) Rsu Mayjen Ha Thalib Kabupaten Kerinci. Jurnal Kesehatan Andalas. Volume; 8 No 2

(6) Anief, 2000.Ilmu Meracik Obat Teori dan Praktek, Yogyakarta: Gadjah Mada University Press. Hal 210-211.

(7) Haliman, Arifdan Ari Wulandari, 2012. Cerdas Memilih Rumah Sakit (Sebuah Komunikasi Medical yang Jujur dan Harmonis). Yogyakarta: Andi Publisher.
(8)Menteri Kesehatan RI, 2018. Peraturan Menteri Kesehatan Republic Indonesia No 4 Tentang Kewajiban Rumah Sakit Dan Kewajiban Pasien. Jakarta.

(9) Dirjen Binfar dan Farkalkes. 2010. Buku Pedoman Penyusunan Formularium Rumah Sakit bekerjasama dengan JICA. Jakarta : Kementrian Kesehatan RI.

(10) Menteri Kesehatan RI, 2016. Peraturan Menteri Kesehatan Republik Indonesia No 72 Tentang Standart Pelayanan Kefarmasian Di Rumah Sakit, Jakarta.

(11) Komite Farmasi dan Terapi RSBMS.2018. Formularium RS Bedah Mitra Sehat volume 01 dengan surat keputusan nomor 307/KPTS/RSBMS/2018. Lamongan.

(12) Budiarto,Ikhsanudin W. 2016. Evaluasi Kesesuaian Peresepan Pasien Rawat Inap Terhadap Formularium di RSUD Karanganyar. Karya Tulis Ilmiah Universitas Muhammadiyah. Surakarta 